\title{
Impressions Gained on a Recent Trip Abroad
}

\author{
By NORMAN KLASS, B.A., M.B., D. Phys. Med. \\ Head of the Physical Medicine at South Rand, Nigel, Germiston and Far East Rand Hospitals \\ and Assistant at the General Hospital, Johannesburg. \\ RESUME OF A TALK GIVEN TO THE SOUTHERN TRANSVAAL BRANCH OF THE \\ PHYSIOTHERAPY SOCIETY.
}

\section{Israel.}

The first place I visited was Israel. Physical Medicine is vibrantly alive in this new country. The University has a Professor of Physical Medicine; there are several Assistant Professors of Physical Medicine; and the Medical Students receive a very sound grounding in our subject.

Although the professorial staff are supposed to be parttime, they spend practically the full working day at their posts, and commence seeing private patients at the time when we cease work for the day. There are also several full-time Registrars, so that a great deal of research work is being done.

There is a school of Physiotherapy of which the head, Sandra Saber, is a former student of, and teacher at Wits. University.

Physiotherapy students have a very practical and well organised 4 year course and their qualification is recognised by the Chartered Society of Physiotherapy.

The Occupational Therapy department at the Sarafend Hospital was one of the best 1 have seen anywhere. It caters mainly for polios.

Two extremely useful "articles" I saw there were a little trolley driven by batteries, for collecting patients from the different wards, and a "gallows" chair, in which the seat and back and gallows part can all be adjusted for polio patients to sit in or for their re-education in walking.

It is a very considerable improvement on the one used at Stoke, Mandeville. The Occupational Therapy Department makes practically every splint, caliper and appliance needed in the whole hospital.

A great convenience-in all the hospitals dealing with polio patients is that the toilets have swing doors, and at the W.C. seat there are horizontal and transverse bars at different heights so that handicapped patients can assist themselves.

Hydro Therapy plays a very large and extremely important part in physiotherapy treatments in this, and every other country I visited, except in England and, unfortunately, as in South Africa. The bath at the Sarafend Hospital cost $£ 75,000$ - a gift from a Canadian Women's Organizationand has parallel bars and numerous appliances in it. In addition, it has electrically operated gantries to move the patient from the stretcher to the bath, with the minimum of effort and handling.

There are weekly conjoint meetings of Physicians, Surgeons, Orthopaedic Surgeons. Specialists in Physical Medicine, Physiotherapists and Occupational Therapists, to discuss interesting patients of the week.

The Society dealing with our subject consists of Physical Medicine, rheumatology and rehabilitation, so that the field is very fully covered.

Turkey.

I next visited the University of Istanbul. Turkey is a very poor country and although a very old one it is only now beginning to take an active part in Physical Medicine, but it is doing so extremely well and is already far ahead of anything done in South Africa, and of practically everything done in England.

Here again, there are Professors of Physical Medicine, Assistant Professors, and numerous full time Registrars. Here again, also, a great deal of Research Work is being done, and I was shown a machine which, it is claimed, stimulates only the sympathetic nerves, but not the voluntary nerves.
There is no Physiotherapy school yet, and the work is done by girls who are picked by the Professorial Staff, and they are taught under their supervision. Hydro Therapy plays a very important part in treatment, and an excellent idea here is to have all the hemiplegias, paraplegias, and similar conditions concentrated in one ward.

Medical students receive a sound grounding in Physical Medicine.

I was shown several patients who had had flexion contractures of their knees, who had been manipulated anc splinted, and for whom good results are claimed.

An interesting innovation here was a form of conveyor belt let into the floor of the gymnasium, on which patients practice walking. It can be set to move at different speeds. An improvement on this was seen in several hospitals in Scandinavia. This can be tilted up to give resistance to walking.

Like in Israel, and all other countries visited, except England, there are weekly conjoint conferences of Specialists in Physical Medicine, Surgeons, Physicians, Orthopaedic Surgeons, Physiotherapists and Occupational Therapists, who examine and discuss and treat patients.

The speciality here is called Physical Medicine and Rehabilitation. Incidentally, medical students are charged no fees in Turkey, so that all of the 3 Universities there are at least 500 students each year.

I was asked to lecture at the University on methods of treatment used in South Africa with particular reference to polio, of which they had had a recent severe epidemic. I was scheduled to speak for one hour, but at the end of this time there were still so many questions and so much discussion that I was kept for $2 \frac{1}{2}$ hours. I was even asked how much my practice brings in annually.

A Workmen's Compensation Act has just come into being and great efforts are made to rehabilitate all handicapped individuals.

Italy.

Rome was the next place I visited. As far as I could learn 'the standard of Physical Medicine is poor and receives but scant attention. There is a hospital about 15 miles south of Rome which treats acute polios, and where the methods are similar to ours.

It was interesting to note that in every country I visited, including England, more and more electrical stimulation is being used in the treatment of polio.

A Professor of Rheumatology in Rome demonstrated some of his treatment to me in arthritic and other conditions in his private Consulting Rooms. This consisted of giving what appeared to be a counter-irritation with an instrument that looked like a small fakir's bed, and then rubbing a powder into the puncture wounds. When I tried to discover what this powder was, the Professor suddenly became very deaf. He also gave deep X-Ray Therapy treatment, even to a spine which had recently been fractured. Yet the amazing thing is that the patients, one and all, said they were feeling considerably better.

The Orthopaedic section of the Rome University is a most magnificent institute. Here I was shown a machine for applying gradual and graduated stretching to flexion contracture of knees, and which was also claimed to give excellent results. 


\section{Switzerland.}

The next port of call was Zurich. Switzerland has excellent Physiotherapy Schools at all three Universities. They have Professors of Physical Medicine, Associate Professors, and full-time Registrars and Medical Students are well taught in Physical Medicine. The group consists of Specialists in Physical Medicine and Rheumatology, and here also, regular weekly conferences are held by Specialists in Physical Medicine, Surgeons, Orthopaedic Surgeons and all ancilliary staff. A great deal of research work is also being done.

It takes longer to specialise in Physical Medicine than any other subject, namely 5 years for Physical Medicine, and an extra 2 years for Rheumatology.

Hydro Therapy, as in all other progressive countries, plays a most important part in treatment. The Physiotherapy Department at the Canton Hospital in Zurich is at least 3 times the size of the one at the General Hospital, although it has many less beds. There are 60 physiotherapists on the staff, which means about one for every 15 in-patients. 'Comfort of patients is considered to such an extent that they even have electric hair driers and numerous bathrooms for patients to use after treatment. All infra-red lamps here are fitted with filters and I saw a most ingenious apparatus for treatment with moist heat. If a physiotherapist wants to do research work she is given every facility to do so.

Physiotherapists in Switzerland work in cycles of 11 days, during which time they must do 88 hours work. Yet their salaries, like salaries in every country I visited, are lower than those paid in South Africa, whilst Income Tax is considerably higher.

\section{Austria.}

Next I visited Vienna where I worked with the world famous Professor Bohler. Physiotherapy does not appear to be used much except for rehabilitation and exercise classes. Professor Bohler proudly points to 4 large notices on all four walls of the gymnasium which read that "if any movement gives pain that movement must not be given."

\section{Scandanavia.}

Next I visited Copenhagen, Stockholm and Oslo, where procedure is so much alike, that I will describe only Copenhagen as an example of all three countries. All three countries have Professors, Associate Professors, and full time Registrars.

The Group is called Physical Medicine and Rheumatology. Medical students receive a good grounding in our subject, and Physiotherapy Schools, especially in rehabilitation exercises are world famous.

Denmark had a very severe polio epidemic about 8 years ago, and it is a revelation to see how well sufferers from this disease are treated and looked after for the rest of their lives. Proprioceptive Neuromusclar Facilitation technique is used a great deal, and the treatment of acute cases is no different from the methods we use in South Africa.

The wards in the acute fever hospitals are so constructed that visitors can look in and see the patients whilst the patients cannot see outwards. For every bottle of beer sold by the Tuborg Brewery a certain percentage comes to the Polio Foundation. I was offered a 6 months scholarship to study Polio in Scandinavia and in the United States, but had, most reluctantly to refuse, not being able to leave my practice for so long.

1 saw a young Eskimo boy who had polio. He and 10 other patients who would have been in an iron lung continuously in this country were sitting in the garden with the assistance of small portable machines.

I also saw a beautiful toy farmyard of which every single article, including long picket fences, were made by a young girl who can only use her toes, as a result of polio.

I saw a most amazing electrically controlled wheel-chair which can be made to move in any direction by merely extending the fingers of one hand-the only movement this polio patient had-against 4 press button switches. I also saw a most interesting paraplegic bed with a curved projection at the foot. By merely lifting the head of the bed the patient is enabled to stand without leaving his bed. Hydro Therapy is used very extensively.

I saw most interesting clothes for both men and women which can be put on with the minimum arm and hand movement, and all reinforced in areas where crutches or appliances may chafe the cloth.

\section{England.}

Finally I visited England, and found Physical Medicine, with very few exceptions being practised as it has been done for years. But a great deal of research work is being done, and proof found that many of our modalities are of very little scientific or clinical value when put to controlled tests.

Every teaching hospital has several full time Registrars yet they seem to do very little research. In the whole of South Africa there are only two Registrars posts.

It was interesting to find at St. Thomas' Hospital that Orthopaedic Surgeons were referring patients to the Physical Medicine Department for diagnosis.

More and more Specialists in Physical Medicine and General Practitioners seem to be practising Dr. James Cyriax's manipulations. I found this in Scandinavia as well. In the same way more and more doctors are going in for giving epidural injections. It was sad to hear that a bath which was built at St. Thomas' only a few years ago is hardly ever used for treatment, and Hydro Therapy appears to be little practised. It was illuminating, and disconcerting, to find that controlled experiments showed that patients who were given short wave Diathermy; Farradism; Wax Baths; and Infra Red do no better than patients who were given only analgesic tablets and active movements, and that farradic foot baths and flat feet exercises would appear to be useless. (vide "Physiotherapy" June, 1959.)

One Specialist in Physical Medicine is reported to have told his Board of Governers that the hospital did not need a Physiotherapy Department, nor Hydro Therapy, and he is most scathing about what he calls the "dear old ladies" who teach and examine at the Chartered Society. No Specialist in Physical Medicine can be appointed Head of any Department unless he has the M.R.C.P. as well, so that all heads of departments are highly trained, and fully capable of doing research work, which they are doing increasingly. Our speciality should therefore soon be put on a fine scientific basis. The treatment in acute polio is similar to ours except that Physiotherapy Students are taught the Kabat Method.

Dr. Cyriax maintains that the only massage which is of any value is friction massage.

Electro-myography has reached a very high standard in England, and a great deal of research is being done in this. I found that the Proprioceptive Neuromuscular Facilitation method is being used in hemiplegias as well, and even arthritic conditions. The Bobath method is also being employed, for hemiplegias and allied conditions.

At St. Thomas' Hospital ultra-violet treatment is being given with long fluorescent type burners, so that all areas can be done at one time. I saw these at this hospital 5 years ago, and on my return recommended that they should be purchased for Transvaal Provincial Hospitals, but without success thus far.

It is a great pity that there are no Professors in Physical Medicine in England and that conjoint conferences between all doctors and ancilliary staff are not held.

\section{Conclusions.}

I come to the following conclusions, from what I have seen. The nature of physiotherapy is at long last definitely beginning to change. It is high time that this should happen as our department is still very largely being used as a dumping ground for all those patients of whom the other Specialities want to be rid. We are completely to be blamed for this as we have gaily continued to use methods of treatment which have no proven scientific basis. It is therefore no wonder that people like chiropracters have stolen a march on the Medical Profession. 


\section{VACANCIES}

\section{NATAL PROVINCIAL HOSPITALS SERVICE.}

1. Applications are invited from suitably qualified persons for appointment to the undermentioned post.

2. Applications should be forwarded to the Director of Provincial Hospitals, P.O. Box 20, Pietermaritzburg, and the reference number shown below against the post, should be quoted.

3. Application forms (P.H. 9) are obtainable from any Provincial Hospital in Natal or from the Director at the above address

4. The names of two referees must be submitted.

5. The closing date for the receipt of applications is February 29th, 1960.

\section{DURBAN—Addington Hospital.}

Plysiotherapist Grade II.

Reference No.: 40/4/22/3.

Salary Scale: $£ 480 \times 30-720 \times 40-800$.

Qualifications:-Diploma in Physiotherapy/Registration or eligibility for registration in Physiotherapy with the South African Medical Council.

Previous experience:-Recognition is granted for previous experience on an approved basis.

\section{CANADA.}

Female Physiotherapist (fully qualified).

386 bed, modern, fully accredited, general hospital. Salary from 3,300.00 dollars per annum, 38 hour week, 3 weeks vacation, excellent personnel policy.

Passage money will be advanced as loan to be repaid by payroll deduction during first year of employment.

Apply: Mr. R. A. Jones,

Business Manager,

St. Thonas-Elgin General Hospital,

St. Thomas, Ontario, Canada.

SOUTHERN RHODESIA-Bulawayo.

Physiotherapist required for Private Practice,

Apply: Masefield, Medical Centre, Bulawayo.
(Continued from Page 5.)

\section{Conclusions: "RECENT TRIP ABROAD"}

Manipulations are being used more extensively, especially in England and Scandinavia. In the same way injections are being used more and more. All our usual methods of treatment are being soundly investigated. More and more attention is being given to general rehabilitation, instead of concentrating on small isolated areas.

It is no wonder that when I was in the R.A.F. the soldiers used to refer to Physiotherapists as the "Pat and Tickle People" and "those who rub you up the wrong way".

We should practise Hydro Therapy very much more than we do, and research work should be done constantly both by medical men and physiotherapists.

Physiotherapists, in my opinion, should have a different carriculum, without zoology, much less anatomy and physiology and practical instead of theoretical psychology. They should be taught Proprioceptive Neuromuscular technique pari passu with the teaching of other clinical work.

1n my opinion they should receive at least a year's training in Kinesiology, such as is taught in the Physical Culture courses in Pretoria and Stellenbosch Universities.

\section{ADVERTISING}

\author{
SPACE
}

\section{AVAILABLE}

